I Universidade de São Paulo (USP), Departamento de Sociologia,

\title{
PERTURBAÇÕES: FOUCAULT E AS CIÊNCIAS SOCIAIS*
}

Foucault visitou o Brasil, não poucas vezes, entre I965 e I976. A primeira, em razão de um convite do Departamento de Filosofia da antiga Faculdade de Filosofia, Ciências e Letras da Universidade de São Paulo, iniciativa de um docente, Gérard Lébrun, que havia sido seu aluno. Na época, era quase desconhecido no milieu acadêmico brasileiro, cujo debate intelectual gravitava em torno das diferentes correntes do marxismo. Veio para ministrar curso sobre obra que se encontrava no prelo, As palauras e as coisas (I966). ${ }^{\mathrm{I}}$ Retornou ao Brasil em I973, para um ciclo de cinco conferências na Pontifícia Universidade Católica do Rio de Janeiro, ${ }^{2}$ e no ano seguinte, para novas conferências no Instituto de Medicina Social, da Universidade Estadual do Rio de Janeiro. Em I975, a convite da USP e por iniciativa de José Augusto Guillhon de Albuquerque, veio dar um curso sobre Vigiar e punir, infelizmente não concluído. ${ }^{3}$ Pouco tempo depois, mas já no ano seguinte, retornou para outro ciclo de conferências em Salvador, Recife e Belém, sem que o mal-estar entre o intelectual e as autoridades brasileiras, decorrente de seu protesto contra a morte do jornalista Vladimir Herzog, se tivesse dissipado.

Não é preciso dizer que a presença de Michel Foucault na universidade brasileira sempre foi objeto de enorme curiosidade e inquietação intelectuais. Afinal, ele era, tal como outros intelectuais franceses - Sartre e Aron, para lembrar alguns dos mais notórios - o que hoje se reconhece como intelectual público, personagem não apenas voltado para a discussão de questões sociais e 
políticas contemporâneas, mas também capaz de aliar atividade intelectual e militância política. A título de exemplo, basta lembrar sua inserção e as inúmeras iniciativas no Group d'Information sur les Prisons - GIP ou um curto texto, publicado originalmente em Libération, em I984, no qual afirmava: "existe uma cidadania internacional que tem seus direitos, que tem seus deveres e que engaja contra todo abuso de poder, qualquer que seja seu autor, quaisquer que sejam as vítimas. Antes de tudo, somos todos governados e, nesta medida, solidários" (Foucault, I994: 707-708). ${ }^{4}$ Não sem motivos, Foucault reconhece no domínio dos direitos humanos esse tipo de cidadania internacional cujos exemplos são tomados de organizações como Anistia Internacional, Terra dos Homens e Médicos sem Fronteiras.

Não foi de menor impacto a chegada ao mercado editorial brasileiro da tradução de Vigiar e punir, em I977 pela Editora Vozes, curiosamente com o subtítulo "história da violência nas prisões", inexistente no original francês, cujo subtítulo é "o nascimento da prisão". As pesquisas de Foucault sobre prisões, manicômios, medicina social, políticas de saúde, sexualidade, loucura, cidades, formas múltiplas de controle social logo pareceram oferecer elementos explicativos poderosos e inovadores para dar conta das singularidades daqueles que justamente pareciam não ter história: delinquentes, loucos e todos os internados em instituições de contenção social, prostitutas, crianças abandonadas, mendigos, dependentes de drogas. Mais do que isso, as investigações históricas de Foucault prestavam-se a iluminar a natureza opressiva e cruel das instituições violentas de contenção e reparação da ordem pública, ao substituir o recurso a outros modelos de interpretação e explicação ancorados seja no reconhecimento da anomia dos arranjos institucionais ou da existência de conflitos de classe encastelados naquelas instituições. Como essas perspectivas ofereciam mais problemas do que soluções, as assertivas de Foucault vieram preencher lacunas teóricas e oferecer hipóteses para investigação empírica. ${ }^{5}$

Como procurei sugerir anteriormente (Adorno, I99I), a natureza dessas apropriações revela mais problemas do que cogitavam suas virtudes. Não raro estudos nos campos da justiça criminal, da família, da educação, da saúde, da sexualidade e da cidade operária buscavam mesclar contribuições das tradições clássicas e mesmo contemporâneas das ciências sociais, em especial da sociologia, com outras, extraídas da investigação histórica de Foucault. Estudos sobre justiça criminal e prisões associavam tais contribuições à teoria das organizações sociais ou aos clássicos estudos no domínio do interacionismo simbólico, nomeadamente à obra de Erving Goffman Asylums: essays on the social situation of mental patients and other inmates (I96I). Por sua vez, estudos sobre a cidade operária estabeleciam uma espécie de convergência entre a obra do historiador E. P. Thompson, sobretudo seu livro The making of the English working class (I963), com sua nítida filiação ao marxismo, e os relatos históricos sobre cidades, sobre políticas de saúde e mesmo sobre os estágios iniciais da forma- 
ção da classe operária na Europa, mais propriamente na França. Se é certo que esse diálogo é passível de ser estabelecido - o próprio Foucault, aliás, sempre recorreu ao diálogo com autores e obras imersos em distintas vertentes teóricas, embora de forma dissimulada e nem sempre visível a olho $\mathrm{nu}^{6}{ }^{-}$, sua mescla produz efeitos, por assim dizer, distorcidos. Por exemplo, confunde-se o problema da sujeição e do assujeitamento com o problema da dominação política, o da perpétua batalha de forças com o da luta de classes, a natureza positiva do poder com sua faceta repressiva e de negação que remete às raízes liberais da filosofia política moderna. Em suma, essas distorções se dão, em grande medida, por força de uma compreensão estreita das implicações teóricas e metodológicas subjacentes à obra e ao pensamento de Michel Foucault.

Logo que ingressei nos quadros docentes da Universidade de São Paulo, junto ao Departamento de Sociologia, passei a ministrar disciplina no Programa de Pós-Graduação em Sociologia, que explorava as relações entre legalidade e moralidade na construção da chamada ordem social burguesa. A disciplina estava sobretudo ancorada em bibliografia histórica, cujos objetos empíricos possibilitavam justamente tratar das tensões entre lei e moralidade, um tema por assim dizer consolidado na sociologia clássica e contemporânea. Parte da bibliografia era consagrada à leitura crítica de algumas obras de Foucault, entre as quais Vigiar e punir (I975), e aos estudos históricos sobre soberania e governamentalidade, cidades e políticas de saúde. Aos poucos, fui-me convencendo de que havia uma espécie de desencontro entre o que diziam as obras do pensador francês e o modo como os estudos históricos empíricos incorporavam suas descobertas e assertivas. Portanto, impunha-se estudar de forma detida a obra de Foucault, ao que passei a me dedicar nos anos subsequentes, reorganizando o conteúdo programático da disciplina. A investigação e a leitura concentrada da obra fizeram-me atentar para a complexa problemática do sujeito e da subjetividade, materializada na provocativa tese da morte do homem (Foucault, I966), uma espécie de norte a partir da qual passei a compreender os múltiplos objetos empíricos tratados da arqueologia à hermenêutica.

Meu contato prolongado com o pensamento de Foucault deveu-se, em verdade, a um certo incômodo intelectual. Eu havia sido formado - e bem formado - na melhor tradição das ciências sociais, isto é, pensar o estudo das sociedades humanas como ciência, essa grande narrativa - dotada de rigor, objetividade, fundamentação teórico-metodológica, controle de variáveis intervenientes - capaz de dissipar o erro, diferenciar ideologia e realidade, desconstruir o primado do senso comum para, em seu lugar, justapor a soberania da verdade racionalmente construída pelo parcimonioso emprego do método científico. A despeito das singularidades das ciências sociais, minha formação esteve imersa completamente no "espírito científico" de nossa época. Ora, o contato com a obra de Foucault começou a perturbar essas familiaridades aceitas e compartilhadas na comunidade de cientistas sociais. Não para as destruir 
e desacreditar, mas para abrir a investigação empírica e a reflexão teórica para novos horizontes ou, como diria Foucault, para poder pensar diferentemente. Essa possibilidade - a de pensar diferentemente - está na origem das profundas perturbações que o pensamento de Foucault aportou para o domínio das ciências sociais e das humanidades.

O propósito deste artigo é inventariar algumas dessas perturbações a partir de uma espécie de equação determinada: a das relações entre sujeito, história, poder e verdade, centradas em torno da arqueologia e da genealogia. É esse percurso que possibilitará passar em revista algumas questões, como o estatuto das ciências sociais - ciências ou saberes? - o lugar da investigação histórica, as relações entre corpo e alma (matéria versus espírito), a investigação como atitude experimental, a provocação como animus da curiosidade científica, a invenção como leitmotiv da reconstrução da realidade social, os embates entre poder e resistência. Por fim, um percurso que deve conduzir a algumas breves considerações sobre o estatuto da crítica.

\section{SUJEITO, HISTÓRIA, PODER E VERDADE: DOIS MODOS DE SUBJETIVAÇÃO}

Em uma de suas mais célebres intervenções, já no final de sua vida, Foucault manifestou: "procurei antes de tudo produzir uma história dos diferentes modos de subjetivação do ser humano em nossa cultura; tratei, nessa perspectiva, de três modos de objetivação que transformam os seres humanos em sujeitos. [...] Não é, então, o poder, mas o sujeito, que constitui o tema geral de minhas investigações" (Dreyfus \& Rabinow, I984: 297-298).

Uma primeira pista aparece, desde já, nesse pequeno texto. Foucault estabelece uma relação entre sujeito e modos de subjetivação. Identifica, ao menos, três modos de subjetivação: a relação entre o sujeito e o conhecimento, a relação do sujeito com o poder e a relação do sujeito consigo mesmo, correspondentes a três arranjos metodológicos distintos, porém interligados: arqueologia, genealogia e ética. ${ }^{7}$ O primeiro desses modos está centrado na análise dos discursos ou, mais propriamente, "em descrever historicamente os procedimentos pelos quais, na história, discursos de verdade transformam, alienam, informam sujeitos, e pelos quais subjetividades se constroem, constituem fonte de preocupação a partir de um discurso-verdade" (Davidson \& Gros, 2004: I 2). Ele recobre as quatro primeiras obras de maior envergadura, publicadas entre I96I e I969: História da loucura na era clássica ([I96I] 2010), O nascimento da clínica ([I963] I997), As palauras e as coisas (I966) e Arqueologia do saber ([I969] I972). Em todas elas, um tênue e discreto fio de preocupação: como, a partir de quais regras, são os sujeitos levados a acreditar na partilha do mundo entre o que parece ser e o que é, entre o senso comum e a realidade, entre o erro e o conhecimento verdadeiro, entre crenças e razão?

Esse primeiro modo de subjetivação já foi exaustivamente tratado por comentaristas e seus críticos. ${ }^{8}$ Não é o caso de repertoriar as questões contidas nessa bibliografia; todavia, importa reter algumas formulações, pois que rela- 
cionadas com os propósitos deste artigo. Elas remetem, pelo sim ou pelo não, às relações do pensamento de Foucault com os principais cânones do pensamento moderno, em especial Descartes, Spinoza e Kant. Fundamentado em Nietzsche, Foucault vai justamente perturbar os alicerces constitutivos do conhecimento, tal como construído pela filosofia moderna, baseados na harmonia entre as coisas a conhecer e o ato de conhecimento. Sob essa tradição filosófica, conhecer é, por conseguinte, um ato que flui a partir de determinadas faculdades do sujeito. Enquanto tal, o homem, portador dessas faculdades, comparece à filosofia moderna como à própria sede da razão, fonte de progresso e de liberdade. Conhecer diz respeito, nesse sentido, aos atos pelos quais o homem, sujeito racional por natureza e excelência, domina o mundo externo e tudo o mais que gravita à sua volta. Enquanto tal, todo conhecimento nasce no homem, passa pelo homem e retorna ao próprio homem. Essa circularidade, garantida pela unicidade do sujeito do conhecimento - decorrente da identidade entre as condições de experiência e o objeto de experiência -, se estende e ganha amplitude justamente pelo trabalho da razão, por uma espécie de racionalidade que lhe é intrínseca e que tudo domina com o propósito de assegurar a soberania do homem em um mundo no qual é permanentemente confrontado pelas paixões, pelos instintos, pelos preconceitos, pelas violências de todo tipo. Nessa medida, toda a questão filosófica acaba centrada no eterno aperfeiçoamento racional da razão; sua razoabilidade na evolução técnica; e sua pertinência no desejo incomensurável de mais e mais liberdade. Nada há de fato a conhecer; como tudo está previamente dado, resta ao conhecimento descortinar os objetos em seu movimento incessante. Sob essa perspectiva, o louco só pode aparecer como o outro da razão; o nascimento da clínica moderna como resultado inevitável do progresso técnico-científico da ciência médica; as ciências humanas como resultado, igualmente inevitável, da progressiva apropriação da sociedade pelo mundo científico.

Foucault vai opor a essa espécie de armadura da razão as proposições de Nietzsche. ${ }^{9} \mathrm{O}$ conhecimento não é o mais nobre dos atributos humanos. $\mathrm{O}$ conhecimento é uma invenção. ${ }^{\text {Io }} \mathrm{E}$ cita um texto de Nietzsche: "em algum ponto perdido do universo, cujo esplendor se estende por incontáveis sistemas solares, houve um dia um planeta no qual animais inteligentes inventaram o conhecimento. Foi o instante mais arrogante e mentiroso da história universal" (Foucault, I994, II: 542-543). O conhecimento não é o resultado do apaziguamento dos instintos; porém, ele é justamente o desfecho dos embates, confrontos e lutas entre os instintos. Ao contrário do que advogava a filosofia moderna e, especialmente, Kant, não há identidade ou continuidade entre conhecimento e natureza humana, entre o corpo e a verdade. Ao contrário, na base do conhecimento encontram-se o ódio, a discórdia, a dissimulação, a hostilidade, o erro tomado por verdade. Conhecer é um ato de violência. E mais, Nietzsche, opondo-se a Spinoza, chega a afirmar que intelligere resulta de um jogo, uma 
espécie de compensação, entre ridere, rir; lugere, deplorar; e detestari, detestar (Foucault, I994, II: 548). Como consequência, se o conhecimento é uma engenhosa fabricação, o sujeito não existe. E tudo o que se supunha ser atributo do conhecimento, desde Descartes - logocentrismo, semelhança, adequação, felicidade, unidade -, é quimera. O conhecimento não tem natureza própria ou uma essência particular, tampouco resulta de regras universais. É produto histórico sob condições determinadas, externas e estranhas à ordem do conhecimento em si. O conhecimento é sempre uma certa relação estratégica na qual o homem está confrontado. Segundo Foucault (2002), "o que pretendo mostrar nestas conferências é como, de fato, as condições políticas, econômicas de existência não são um véu ou um obstáculo para o sujeito do conhecimento, mas aquilo através do que se formam os sujeitos de conhecimento e, por conseguinte, as relações de verdade".

Sob essa perspectiva, faz mais sentido falar em política do conhecimento. ${ }^{\text {II }}$

Ao demonstrar que o sujeito transcendental é pura invenção encadeia-se outra série de desarranjos em nossas convenções e nossos hábitos intelectuais. Por certo, um dos mais evidentes é a crítica ao humanismo, cuja vigência nos meios acadêmicos é de longa data, remontando às heranças do pensamento iluminista. Em entrevista, Foucault (I994, I: 5I4) afirma:

o humanismo foi uma maneira de resolver, nos termos da moral, de valores, de reconciliação, os problemas que não se poderiam absolutamente resolver. Você conhece o dito de Marx? A humanidade só propõe os problemas que ela pode resolver. Pois eu creio que se pode dizer: o humanismo finge resolver problemas que ele não pode propor! [...] Nossa tarefa atualmente é libertarmo-nos definitivamente do humanismo, e, nesse sentido, nosso trabalho é um trabalho político. ${ }^{\text {I2 }}$

Por conseguinte, com esse trabalho "político" de desconstrução do sujeito transcendental, Foucault se propôs escapar das armadilhas da filosofia do mesmo, aquela cujo pressuposto fundamental é o trabalho da razão, promovendo o reencontro do homem com sua própria essência, uma vez perturbado pelos erros, preconceitos, crenças e paixões. Tratar o homem exclusivamente pelo que faz - no trabalho, na vida, na linguagem -, sem considerações a priori, sem pressupor uma natureza oculta que precisa ser decifrada e trazida à luz pelo trabalho incessante da razão, se transforma, neste momento, em uma das exigências da nova política do conhecimento.

Todavia, um dos mais contundentes desarranjos aponta justamente para a crítica arqueológica do evolucionismo histórico. Uma história arqueológica é uma história dos saberes e não da ciência (Foucault, I969), distinção cujo alcance será tratado mais à frente. Esse estatuto revela, ao menos, duas características: primeiramente, sua positividade. Uma história dos saberes transcende as fronteiras disciplinares, recorta campos teóricos e conceituais constituídos a partir de distintas tradições, acolhe tanto proposições classificadas como científicas quanto pré-científicas. É, nessa medida, uma história globalizante, pois 
um mesmo quadro histórico (Renascimento, Era Clássica em meados do século XVII e Era Moderna em finais do século XVIII e século XIX) pode ser regido pela articulação de diferentes saberes. Segundo Foucault (ı 966: I3), "a ordem sobre a qual nós pensamos não tem o mesmo modo de ser daquela dos clássicos". Ao mesmo tempo dotada de profundidade, pois é fundada em um "a priori histórico". ${ }^{13}$ Estas características, história dos saberes em lugar de história das ciências, globalidade e profundidade diferenciam uma história arqueológica das formas convencionais com que os historiadores lidam com a história.

Dadas essas características, a história arqueológica coloca para o investigador o problema da descontinuidade, um modo contundente de exercer a crítica contra o evolucionismo, a continuidade e a recorrência. O horizonte da história arqueológica não é o passado como projeção para o futuro, mas para o presente, para a atualidade (Ewald, I997). Ela suspende a atualidade da ciência como critério para julgamento de um saber sobre o passado. Não está voltada para definir ou fundamentar as condições de validade dos saberes, porém para percorrer as condições e possibilidades históricas que tornam os saberes vetores da verdade. É oportuno lembrar toda a démarche histórica que Foucault (I963) promove em sua investigação a respeito do nascimento da medicina moderna. Portanto, a história arqueológica já apontava para uma démarche que introduz, por assim dizer, um segundo modo de subjetivação: a história não como lugar de apaziguamento, mas como lugar de batalhas e lutas incessantes, em termos de práticas tanto discursivas quanto não discursivas (Foucault, I970) em torno da verdade. É justamente nesse momento que o pensamento de Foucault transita da arqueologia para a genealogia, do discurso para o poder, das regras de formação dos enunciados para os confrontos de forças que fundam modos de ser e as práticas discursivas.

Esse segundo modo de subjetivação alcança a aula inaugural no Collège de France, L'ordre du discours, de I970, duas obras fundamentais, Surveiller et punir: naissance de la prison (I975) e La volonté de savoir ([I976] I977), a par de uma série de entrevistas, intervenções e pequenos ensaios que compõem o volume II (I970-I975), o volume III (I976-I979) e parte do volume IV (I980-I988) de Dits et écrits, publicados em I994, além dos cursos no período de I970 a I980. ${ }^{\text {I4 }}$ É nesse conjunto de escritos que Foucault explora as relações entre poder e verdade. A ordem do discurso é texto com estatuto preciso: por um lado, uma espécie de balanço dos resultados da investigação arqueológica, seus alcances e achados, mas também seu esgotamento; por outro, lançamento do programa de investigação genealógica. Parte substantiva da aula é dedicada à reflexão crítica sobre os modos de regulação e controle de produção de discursos, enfeixados em torno de três grandes sistemas de exclusão: a palavra interdita, a partilha da loucura e a vontade de saber. Foucault reconhece que tratou mais longamente da vontade de saber. A respeito, ele indaga: "a razão disso é talvez esta: é que, se o discurso verdadeiro não é mais, desde os gregos, aquele que 
responde aos desejos ou aquele que exerce o poder, na vontade de verdade, na vontade de dizer, esse discurso verdadeiro, o que é então que está em jogo senão o desejo e o poder?" (Foucault, I97I: 22).

Após ocupar-se detidamente, no domínio da vontade de saber, dos procedimentos de controle e delimitação dos discursos (a oposição entre o verdadeiro e o falso, o comentário, o autor, ${ }^{15}$ a organização das disciplinas, o ritual, a "sociedade de discursos", a apropriação social dos discursos), ele se pergunta se alguns temas da filosofia não foram justamente capturados por esse gênero de procedimentos, entre os quais os princípios do sujeito fundador, da experiência originária ou da mediação universal. Ao fazer essa indagação, ele aponta para a possibilidade de ultrapassar esse umbral mediante outros arranjos metodológicos que possam "restituir ao discurso seu caráter de acontecimento" (Foucault, I97I: 53). ${ }^{16}$

Impôs-se, por conseguinte, a formulação de novas questões sob inspiração de outros princípios de método. Impôs-se repensar a história, tendo por fios a descontinuidade, a rareza, a especificidade, a exterioridade. Seus fundamentos e alvos não mais serão a continuidade e a consciência do tempo, o signo e a estrutura: "serão aqueles do acontecimento e da série, com o jogo de noções que lhe são ligadas; regularidade, perigo, descontinuidade, dependência, transformação" (Foucault, I97I: 59). E, prosseguindo, "é necessário elaborar para além das filosofias do sujeito e do tempo - uma teoria das sistematicidades descontínuas. [...] É necessário aceitar introduzir o perigo como categoria na produção dos acontecimentos" (6o-6I). A genealogia toma por objeto o descontínuo, o acaso, a materialidade. Estamos, portanto, em outro território metodológico - não mais como os discursos se constituem, porém por que se formam. Estamos no domínio do poder, instituinte de novas formas de assujeitamento.

Ao final da aula, Foucault faz menção às dívidas para com Jean Hypolite, seu predecessor na cátedra de história do pensamento, que ele converteria em história dos sistemas de pensamento. Em sua homenagem, Foucault escreveu texto de referência para se compreender o estatuto da genealogia: Nietzsche, a genealogia e a história. Para Foucault (I 994, II: I39), "a história ensina também a rir das solenidades de origem". Com essa provocante afirmação e baseandose em Nietzsche, ele questiona a identidade (harmonia) entre as origens (nobres porque "divinas") e a verdade dos fatos históricos. Ao contrário, afirma que o "começo histórico é baixo". Em sua base, encontra-se não a harmonia e a verdade, mas o disparate, o inconfessável, a mesquinhez. Donde o papel do historiador não é fazer a história das origens dos valores, da moral, do ascetismo, mas, ao contrário, fazer a história das meticulosidades e dos acasos dos começos, pôr em relevo as maldades, não ter pudor de descer ao bas-fond da sociedade, de percorrer-lhe os labirintos na busca do inaudito, de tudo o que parece supérfluo e inútil. Sob essa perspectiva, a pesquisa histórica passa necessaria- 
mente pela investigação da proveniência (busca demarcar a dispersão, os desvios, as falhas, os acidentes, os maus cálculos) e pela investigação da emergência (entrada em cena das forças, forças em luta contra outras forças, forças em luta contra si mesmas).

É por isso [conclui Foucault (I994, II: I45-I46) nesse célebre artigo] precisamente que, em cada momento da história, a dominação se fixa em um ritual; impõe obrigações e direitos; constitui cuidadosos procedimentos. Ela estabelece marcas, grava lembranças nas coisas e até nos corpos; torna-se responsável pelas dívidas. [...] E continua: o grande jogo da história será de quem se apoderar das regras, de quem tomar o lugar daqueles que as utilizam, de quem se disfarçar para pervertêlas, utilizá-las ao inverso e voltá-las contra aqueles que as tinham imposto; de quem, se introduzindo no aparelho complexo, o fizer funcionar de tal modo que os dominadores encontrar-se-ão dominados por suas próprias regras. ${ }^{\mathrm{I}}$

Essa perspectiva histórica foi mais bem compreendida por Paul Veyne, como, aliás, o próprio Foucault teria em algum momento declarado. Segundo Veyne (I984: 200),

a instituição inicial de Foucault não é a estrutura nem o corte, nem o discurso: é a "rareza", no sentido latino da palavra; os fatos humanos são raros, não estão instalados na plenitude da razão, há um vazio a seu redor devido a outros fatos que nossa sabedoria não inclui; porque o que é poderia ser distinto; os fatos humanos são arbitrários, no sentido que Mauss atribui a essa palavra. Não são evidentes, ainda que assim pareçam aos contemporâneos e mesmo a seus historiadores a ponto até de uns e outros nem sequer os perceberem.

O método genealógico consiste em perseguir a materialidade empírica dos fatos. Nada pressupor por detrás das ações - a relação de produção, a dominação política, o Estado, a luta pela liberdade. A prática deve ser vista tal como é realmente; ela não é uma instância, como o "elo" freudiano, ou um motor primário, como as relações de produção em Marx. Para Veyne, Foucault não nos convida a tornar visível um discurso misterioso para decifrá-lo; "convida-nos a observar exatamente o que se diz" (Veyne, I984: 2 I I). Sob essa perspectiva, o que efetivamente importa são as forças objetivas de assujeitamento, a mecânica de poder que produz subjetividades assujeitadas, tais como a do criminoso que, na prisão, se converte em delinquente.

Não convém resumir as teses centrais de Vigiar e punir (I975), tampouco rever seus argumentos principais, tão conhecidos que são do público acadêmico. Embora a obra tenha o subtítulo, já mencionado, de "o nascimento da prisão", Foucault não pretendeu escrever a história dessa exemplar instituição de punição do século XIX que perdura até nossos dias. ${ }^{18}$ Como ele sustenta nas páginas iniciais, seu objeto foi fazer a genealogia da alma moderna: "objetivo deste livro: uma história correlata da alma moderna e de um novo poder de julgar; uma genealogia de uma novo complexo científico-judiciário em que o poder de punir toma seus apoios, recebe suas justificações e suas regras, estende seus efeitos e mascara sua exorbitante singularidade" (Foucault, I975: 30). 
Alma, portanto, entendida como correlato de uma técnica de poder. O livro percorre a metamorfose dos métodos punitivos a partir de uma tecnologia política do corpo em que se pode ler uma história comum das relações de poder e das relações de objeto. Daí também o objeto da sanção penal moderna: o corpo e suas forças; "alma, prisão do corpo" (Foucault, I975: 38). O corpo pensado como feixe de forças que possui utilidade econômica e política, extraída por essa tecnologia determinada constituída pelas disciplinas. O poder pensado em sua positividade, a de produzir a delinquência e o delinquente, peças essenciais para compreensão da alma moderna. Daí igualmente as imbricações entre regimes de verdade e regimes de poder (Davidson \& Gros, 2004: 38I), engenhosamente trabalhadas em torno das duas grandes práticas de saber-poder sobre o crime: o inquérito e o exame, bem como por meio de um poderoso mecanismo disciplinar, o panoptismo.

Vigiar e punir (I975) suscitou, cinco anos depois de sua publicação, intenso e acalorado debate, que resultou em inúmeras entrevistas para diferentes veículos franceses e estrangeiros, pequenos artigos de esclarecimentos e polêmicas em torno de questões provocativas, além dos cursos no Collège de France, alguns anteriores à publicação (de I97I a 1975). Suscitou igualmente crescente interesse acadêmico mundo afora, sob a forma de cursos de formação acadêmica, congressos e seminários, artigos na imprensa, em revistas científicas, em coletâneas e obras. Não obstante, Foucault não pareceu encerrar essa etapa da investigação. A partir desse momento, as análises de Foucault caminham em duas direções críticas: por um lado, contra o marxismo, procurando mostrar que o poder não reprime nem interdita; ele excita e produz. Por outro, contra o contratualismo, procurando mostrar que o poder não se confunde com a instauração de uma ordem pacificada por força da lei.

Ao redigir seu projeto voltado para escrever uma história da sexualidade moderna, La volonté de savoir, Foucault ([1976] I977) se deu conta de que outras mecânicas de poder - não necessariamente encerradas em espaços institucionais "fechados", tais como as prisões e os hospitais psiquiátricos eram capazes de produzir verdades e novas formas de subjetividade assujeitadas. Projeto ambicioso, em seis volumes, que não chegou a ser concretizado, e que tinha por propósito analisar a proliferação discursiva sobre o sexo, nas sociedades modernas, capitaneada pela chamada scientia sexualis. Contrariamente às tendências dominantes, em especial nas ciências médicas (psiquiátricas, psicológicas e na psicanálise), Foucault se propunha a questionar a hipótese repressiva, isto é, a suspeita de que, com a sociedade industrial e burguesa - e, em especial com a era vitoriana - o sexo teria sido negado e reprimido. Foucault enxergava movimento inverso. Por isso, seu projeto consistia em

interrogar o caso de uma sociedade que desde há mais de um século se fustiga ruidosamente por sua hipocrisia, fala prolixamente, de seu próprio silêncio, obs- 
tina-se a detalhar o que não diz, denuncia os poderes que exerce e promete liberar-se das leis que a fazem funcionar. Gostaria de passar em revista não somente esses discursos, mas ainda a vontade que os conduz e a intenção estratégica que os sustenta (Foucault, 1977: I4).

Cogitava, assim, investigar as instâncias de produção discursiva, as de produção de poder e as de produção de saber. Trata-se, portanto, de entender quais mecanismos problematizaram a sexualidade moderna, vale dizer "colocaram o sexo em discurso" (Foucault, I997: I7). Por isso, era preciso ir além das paredes do quarto do casal e percorrer as instâncias de circulação de verdades, no divã do psicanalista, nos laboratórios e centros de pesquisa, nos livros e congressos, nas conversas cotidianas. ${ }^{19}$

Por sua vez, em Sécurité, territoire, population (2004), curso oferecido em I977-I978, Foucault aborda a emergência de uma nova racionalidade governamental que elegerá a população como objeto de intervenção, de produção de verdades e de relações de poder. É nesse momento que introduz o estudo do liberalismo como técnica de governo e elabora suas reflexões sobre biopoder e biopolítica. Como ele afirma, no domínio político, ao longo do século XVII, predominavam as teorias filosóficas fundadas na soberania, na lei natural e no contrato social. Todavia, no século XVIII, surge uma tecnologia política coerente que vem rivalizar com as teorias contratualistas. A natalidade, a saúde, a investigação empírica e sistemática do crescimento e das condições históricas, geográficas, demográficas e estatísticas da população se tornam tanto preocupações do Estado, como produção de saberes novos que dão nascimento às ciências sociais modernas segundo o modelo das ciências físicas.

Não haverá um abandono das teorias e técnicas de governo baseadas na lei, na soberania e no contrato; elas serão acopladas a outras técnicas que investem em dois polos: primeiramente, nos corpos individualizados. Preocupação para com os corpos não tanto, ou apenas, como meio de reprodução, porém como objeto a ser manipulado. Trata-se de uma tecnologia política - biopoder -, e o objetivo principal desse poder disciplinar, já abordado em Vigiar e punir (I975), é produzir corpos dóceis. Enquanto tal, as técnicas disciplinares têm por alvo privilegiado os corpos das classes trabalhadoras e do subproletariado urbano, aplicáveis, por conseguinte, nas usinas, nas casernas, nas prisões e nos hospitais, mas não exclusivamente nesses espaços institucionais, pois se desenvolvem também nas escolas e nas universidades. O segundo polo, que se torna mais e mais presente a partir do século XVIII, diz respeito aos corpos como espécie humana. Estamos no domínio da biopolítica, no qual, pela primeira vez na história moderna, são categorias científicas - espaço, tempo e população - que se tornam objeto de atenção política, em lugar das categorias jurídicas. Daí o peso da investigação genealógica a respeito dos controles reguladores dos processos vitais. ${ }^{20}$ 
Procurou-se, até este estágio da reflexão, estabelecer as conexões entre sujeito, história, poder e verdade, focalizando as questões nucleares da arqueologia e da genealogia. Esse encaminhamento teve por objetivo sugerir as démarches e os deslocamentos subjacentes ao pensamento de Foucault, seu modo pouco convencional ou anticonvencional de tratar as clássicas questões das ciências sociais e das humanidades. Em especial, o percurso adotado teve por propósito acentuar o que parece central: a desmontagem do sujeito do conhecimento, a descontinuidade da história, o poder não como propriedade ou atributo, todavia como mecânica - tudo levou ao mesmo lugar: a problematização da verdade. Como afirma Gros (Davidson \& Gros, 2004: I I),

para além dessa diversidade de usos, que reflete a própria diversidade da obra, é possível encontrar um fio condutor que atravessa o conjunto de sua obra e de reorientá-la ao redor de uma interrogação propriamente filosófica. É a questão da verdade. O homem é fundamentalmente pensado na sua obra como um "animal de verdade". Mas Foucault opera um deslocamento importante nessa interrogação.

A parte final deste artigo pretende refletir a respeito de algumas consequências desses deslocamentos para os nossos hábitos e convenções acadêmicos.

\section{DESLOCAMENTOS E PERTURBAÇÕES: O ESTATUTO DA CRÍTICA}

Entre as perturbações, uma parece cara a nós, cientistas sociais. A leitura rigorosa do capítulo final de As palauras e as coisas (I966), intitulado As ciências humanas, problematiza justamente os três modelos constituídos em torno da entrada do homem como "representação" na ordem dos saberes. Entre esses modelos, encontra-se a sociologia. Nessa obra, Foucault sustenta que o homem não é privilégio das ciências humanas, cuja singularidade advém exatamente de um certo modo de tematização do homem que trabalha (economia), do homem que vive (biologia) e do homem que fala (estudo da linguagem), objeto das ciências empíricas. O nascimento das ciências humanas ocorre precisamente quando, no século XIX, se reinventa o espaço da representação (entre o empírico e o transcendental), todavia em termos muito diferentes das heranças da era clássica, pois a configuração do saber é outra. Não se trata de aproximar as palavras e as coisas pelo que as assemelha; a representação na era moderna é de outra complexidade, de outra globalidade e de outra profundidade. Ela não existe senão no âmbito da consciência. Especificamente na sociologia, "tudo se passa como se a dicotomia entre o normal e o patológico tendesse a se apagar em proveito da bipolaridade da consciência e do inconsciente" (Foucault, I 966: 374). Como tal, a sociologia se conforma como a representação do homem no mundo do trabalho. Como esse mundo é caracterizado pelo conflito, a sociologia nasce como modelo de ciência da sociedade constituído a partir de uma mescla entre conflito e regra. O conflito provém do estudo da luta dos homens pela produção e distribuição da riqueza; a regra, dos desdobramentos racionalistas da filosofia moderna. Sob essa perspectiva, a sociologia aparece 
como a ciência capaz de exercer a consciência crítica da sociedade, vale dizer, capaz de promover a regulamentação do conflito.

Ora, ao final desse mesmo capítulo, já apoiado em Nietzsche, Foucault afirma que o homem, essa invenção recente, está em vias de desaparecer. Não faz menção à materialidade do homem, mas a suas formas de representação. Diz respeito à pretensão das ciências humanas ao estatuto de discursos científicos, como fonte por excelência da verdade. No caso da sociologia, sua pretensão de ser a única fala legítima e autorizada sobre as relações dos indivíduos entre si e com a sociedade, mediadas pelo mundo do trabalho, está em suspenso. Ora, se a representação do homem - o humanismo, como já dito - está em vias de desaparecer, a sociologia estaria condenada ao perecimento? Estaríamos nós, sociólogos, iludidos porque envoltos em uma invenção que não resiste à crítica arqueológica dos saberes? Estaríamos não produzindo ciência, porém representações, espelhos do real? Voltamos às perguntas iniciais da filosofia: quem somos e o que, afinal, fazemos na qualidade de comentaristas e intérpretes dos acontecimentos sociais? Não existimos, somos ilações da realidade?

Por certo, essa provocativa análise e seus desdobramentos tinham por efeito atingir a pretensão científica da sociologia, a de se qualificar como aquela instância de conhecimento do "sujeito" capaz de profunda imersão na consciência social ao fazê-lo capaz de dissipar as aparências, dissolver o senso comum, desobstruir os véus ideológicos que perturbavam a relação do sujeito consigo mesmo, com sua essência, com suas virtualidades e virtudes humanistas. Foucault cuidou de condenar ao esquecimento e abandono esse tipo de pretensão; buscou, entretanto, qualificar a sociologia como um saber dos coletivos sociais e das instituições. Em inúmeras passagens de sua obra, a presença de argumentos sociológicos salta aos olhos. Tanto em História da loucura ([I96I] 20I0) quanto em O nascimento da clínica ([I963] I997) aos fatos históricos Foucault agrega a funcionalidade ou disfuncionalidade de instituições sociais (o hospital, a clínica, a formação médica) como elemento que concorreu para mudanças experimentadas nas formações discursivas sobre o louco e sobre a medicina. Em Vigiar e punir (I975) é flagrante o recurso à sociologia para explicar mudanças no emprego do trabalho penal ou mudanças na literatura popular sobre crime e criminosos, e, sobretudo, na análise dos ilegalismos. Foucault não nega o peso da sociedade industrial e burguesa na configuração de forças sociais e políticas cujos confrontos caminharam para a consolidação das tecnologias disciplinares como mecânica de poder na era moderna.

A sociologia, portanto, é pensada como saber e não como ciência. Enquanto saber, ela condensa conhecimentos extraídos de fontes diversas, transversais, que se fixam em práticas institucionais ou não institucionais determinadas. Não busca fixar verdades, porém reunir instrumentos de análise para o reconhecimento de forças sociais cujo jogo entre o verdadeiro e o falso configura modos de ação, estilos de vida, relações de poder, relações de classe e de 
autoridade, assim como produção de símbolos, mitos, convenções culturais. Nessa mesma medida, a sociologia não é uma instância voltada para a regulamentação do conflito, mas é capaz de esclarecer o campo de gravitação de forças que permita entender por que conflitos de determinada natureza - na indústria, na vida doméstica, nas ruas, nos laboratórios, nas universidades têm lugar em nossa contemporaneidade. Perspectivas como essa abrem a imaginação sociológica para horizontes talvez, até há pouco, impensáveis.

Outros deslocamentos, porventura mais pontuais, são identificáveis em Vigiar e punir (I975). Em ensaio denso e muito fundamentado, François Ewald (I975) identifica vários deslocamentos promovidos nessa obra. Seu foco é contrapor o modo como o poder é analisado nas teorias clássicas sobre lei, soberania, contrato e Estado. Em particular, ele sublinha que Foucault se recusa a reduzir as relações de poder como emanações dos interesses de mercado ou projeções, até ideológicas, das lutas de classe. Como dirá, nem totalizar, nem dialetizar. Do mesmo modo, ainda segundo Ewald, o pensador francês recusará ao poder uma essência; em seu lugar, o poder como exercício, como operação, como mecânica. Contra a ideia do Estado como instância por excelência do poder, a funcionalidade dos micropoderes em suas relações com o poder estatal, como, aliás, ficará demonstrado nos cursos de I975 a I978. Na mesma direção, contra a faceta repressiva do poder - o poder que oprime, subjuga, domina - Foucault põe em destaque sua faceta produtiva e positiva, na qual a dominação de uns sobre outros, de classes sobre outras classes constituem efeitos de um processo mais amplo e complexo que são as operações de sujeição, assujeitamento. Não se trata de desconhecer, recusar ou ignorar os efeitos opressivos do poder. Trata-se de questionar a hegemonia dessa ordem de explicação. Foucault integra ambas as perspectivas ao propor um modelo de análise - anatomia política - que é, ao mesmo tempo, uma análise da economia política, isto é, voltada para focalizar as tecnologias produtivas, de produção do poder.

O tema das relações poder/produção revela ainda outra dimensão. De fato, Foucault se recusa a deduzir as relações de poder das relações de produção. Em Vigiar e punir (I975) ele se inspira em proposições contidas em O capital, justamente para inverter os argumentos alusivos às formas de cooperação e disciplina nas fábricas. Na leitura de Foucault, Marx coloca o despotismo do capital, que se confronta com a possibilidade de resistência dos operários, como requisito para a exploração da mais-valia. Foucault inverte essa relação. Para Ewald (I975: I24I), "a análise de Marx apaga assim o que aquela de Foucault faz aparecer: entre a exigência do capital (a mais-valia) e a solução (a oficina disciplinar), há uma anatomia política: a disciplina”. Não foi o despotismo do capital que impôs a disciplina, que, aliás, o precede, pois que ela remete a uma economia política do poder nascida em uma conjuntura bem determinada, marcada seja pela explosão demográfica de finais do século XVIII, 
seja por força do crescimento do aparelho produtivo, que se impunha proteger. Segundo Foucault (I975: 257),

de fato os dois processos, acumulação de homens e acumulação de capital, não podem ser separados; não teria sido possível resolver o problema da acumulação de homens sem o crescimento do aparelho de produção capaz ao mesmo tempo de mantê-los e de utilizá-los; inversamente, as técnicas que tornam útil a multiplicidade cumulativa de homens aceleram o movimento de acumulação do capital. Em um nível menos geral, as mutações tecnológicas do aparelho de produção, a divisão do trabalho, e a elaboração dos procedimentos disciplinares mantiveram um conjunto de relações muito próximas.

Sob essa perspectiva, as disciplinas produziram os corpos economicamente úteis e politicamente dóceis de que, no curso do século XIX, o despotismo do capital se valeu para seus propósitos de exploração. Assim, a sujeição aparece como requisito de exploração. ${ }^{2 I}$

A análise do panoptismo, presente em Vigiar e punir (I975), é dedicada justamente a refletir sobre os processos históricos de consolidação das disciplinas como mecânica por excelência do poder. As raízes se encontram em formas pouco institucionalizadas de moralização da população contra hábitos considerados, nos séculos XVII e XVIII, pervertidos, tais como o alcoolismo, a sexualidade desregrada, a violência incontida nas relações domésticas e de vizinhança. Sociedades de auxílio mútuo, em geral religiosas, com seus rituais e práticas dominicais disseminaram-se pelos cantões da Grã-Bretanha e da França. Buscavam exatamente conquistar as almas recalcitrantes, incutir-lhes hábitos moralmente saneados, incluindo os de temor a Deus, e fomentar-lhes o desejo de uma vida digna, parcimoniosa, autocontida. Para Foucault (I975: 246), "desde a Contrarreforma até a filantropia da monarquia de julho, iniciativas desse tipo se multiplicaram; elas tinham objetivos religiosos (a conversão e a moralização), econômicos (o socorro e a incitação ao trabalho) ou políticos (trata-se de lutar contra o descontentamento ou a agitação)".

Essas práticas, de início desenvolvidas ao acaso e com o propósito de enfrentar problemas locais de desordens sociais dos mais variados tipos, foram pouco a pouco sendo institucionalizadas e afinal estatizadas, em especial pelo trabalho da polícia na França. O que importa destacar é que, no curso de quase dois séculos, foi-se estabelecendo uma espécie de relação de dependência dos indivíduos em face das instituições de controle e de disciplina social. Tais instituições de controle e reparação social foram-se tornando necessárias e, mais do que isso, politicamente imperativas. Não sem razão, por mais criticadas e condenadas junto ao público em geral e à opinião pública especializada, as prisões se impuseram como instituição central nas sociedades modernas, mesmo na era da crise das disciplinas. ${ }^{22}$

O texto de Ewald prossegue examinando as principais démarches teóricas e metodológicas aportadas por Vigiar e Punir (I975), muitas delas já exaustiva- 
mente esclarecidas pelo próprio pensador francês ou por seus leitores e comentaristas. Vale a pena destacar a discussão em torno das constantes do poder. Primeiramente, o poder como uma batalha permanente. "O poder não termina de se exercer, ele não conhece repouso; nada é jamais dado, tudo está sempre por fazer, o poder só se exerce como batalha" (Ewald, I975: I25I). Vide a propósito a análise dos ilegalismos, uma espécie de "motor das transformações na tecnologia do poder" (Ewald, I975: I 252). Mesmo quando, aparentemente, ele pareça estar à salvaguarda das resistências, ele opera como se estivesse movido por elas. E isso, não por força de previsão, prudência ou precaução, porém porque o poder é produtivo, não cessa jamais. Ademais, essa batalha perpétua opera corpo a corpo, com seus investimentos e assujeitamentos, segundo um tipo de materialismo físico, que nada tem a ver com o materialismo histórico ou o materialismo mecanicista do século XVIII. Para Ewald (I 975: I 252I 253), "o poder mobiliza, retoma, inventa sem cessar as matérias de seu exercício. Domesticar a parafernália punitiva é fazer o catálogo dessas ínfimas materialidades". Por tais razões, não há táticas de poder que sejam unívocas, e o poder não tem finalidade, tampouco fim. As tecnologias de poder são da ordem do acaso, do acidental, do imprevisto e imprevisível. Não há um fio condutor que explique quer suas origens, quer seus desdobramentos. Apenas suas meticulosas materialidades é que se levam em conta.

Esses são alguns dos exemplos pelos quais o pensamento de Foucault é desconcertante, no sentido de produzir dissonâncias em lugar de harmonias, surpresas em lugar de certezas, desconforto em lugar de serenidade, indagações mais do que respostas afirmativas e categóricas. Ele revela também esse tom profundamente provocativo, desafiador, às vezes até irônico e sarcástico de não poucos de seus comentários. Não tinha receio de menosprezar alguns de seus mordazes críticos. Por exemplo, criticado pela leitura absolutamente pessoal e livre das proposições de Nietzsche, retrucou:

a presença de Nietzsche é cada vez mais importante. Mas me cansa a atenção que lhe é dada para fazer sobre ele os mesmos comentários que se fizeram ou se farão sobre Hegel ou Mallarmé. Pessoalmente, os autores de que eu gosto, eu os utilizo. A única marca de reconhecimento que se pode testemunhar a um pensamento como aquele de Nietzsche é precisamente utilizá-lo, deformá-lo, fazê-lo ranger, gritar. Então, que os comentários digam se se é ou não fiel não tem nenhum interesse (Foucault, I994, II: 753).

Do mesmo modo, não tinha receio de se desdizer em obras posteriores, de retificar caminhos, de amenizar críticas há pouco apresentadas de forma imperativa e radical. Contra a alegação de que seus livros não pareciam oferecer aos leitores um fio condutor que possibilitasse compreender sua obra, retrucou dizendo que escrever um livro novo era, de certo modo, anular o anterior. Assim também, por exemplo, uma primeira leitura de Vigiar e punir (I975) sugere que Foucault opõe radicalmente soberania e disciplina, lei e norma, con- 
trato e disciplina. Posteriormente, em alguns de seus escritos e entrevistas, essa polarização aparece matizada:

e eu creio que nos encontramos aqui numa espécie de ponto de estrangulamento, que não podemos continuar a fazer que funcione indefinidamente dessa maneira: não é recorrendo à soberania contra a disciplina que poderemos limitar os próprios efeitos do poder disciplinar. [...] De fato, soberania e disciplina, legislação, direito da soberania e mecanismos disciplinares são duas peças absolutamente constitutivas dos mecanismos gerais do poder em nossa sociedade. Para dizer a verdade, para lutar contra as disciplinas, ou melhor, contra o poder disciplinar, na busca de um poder não disciplinar, não é na direção do antigo direito de soberania que se deve ir; mas antes na direção de um direito novo, que seria antidisciplinar, mas que estaria ao mesmo tempo liberto do princípio da soberania (Foucault, 1999: 47).

Na mesma direção, pode-se igualmente constatar que seu labor intelectual não parecia, à primeira vista, se orientar segundo um plano originalmente previsto. A leitura dos cursos sugere, por um lado, um investigador que se deixava levar por pistas oferecidas pelas fontes documentais - relatórios técnicos, memoriais, crônicas de época, registros estatísticos, manuais, livros técnico-científicos, obras filosóficas - sem uma hipótese previamente desenhada a ser submetida à crítica e ao teste de verdade. Um estilo de trabalho rigorosamente experimental, que deixava os objetos se manifestaram em sua exterioridade sem qualquer pretensão de lhes descobrir um sentido oculto a ser decifrado pelo exercício da razão. Tudo parece muito transparente, situado na superfície, mostrado a olho nu, como se fosse acessível a qualquer um. Basta ir à história e olhar. Nada se esconde. O poder não se esconde, ele se insinua por tudo e por todos. Do sexo, falamos sempre mais e mais, ainda que, ressentidos, lastimemos ser reprimidos. Um estilo de conduta intelectual aparentemente anticientífica. Por outro lado, seu estilo narrativo parece perseguir uma espécie de lógica cartesiana, como se deixa entrever pela simples leitura do sumário de suas obras. Na verdade, se traços desse espírito anticientífico podem ser identificados em sua obra em geral, o contrário também pode ser asseverado quando se verifica o quanto suas investigações históricas estavam movidas pela curiosidade, pela vontade de saber e sobretudo pelo exercício exaustivo e rigoroso de seus procedimentos metodológicos. É mesmo surpreendente que os cursos tenham acolhido tantas informações históricas, tenham conferido visibilidade a tantos personagens históricos, muitos dos quais desconhecidos, tenham trabalhado justamente sobre o que parecia não ter história, dispersos que se encontravam sobre o tecido social.

Cabe, por fim, indagar nesse imenso edifício intelectual qual o estatuto da crítica. Foucault ocupou-se da questão em uma conferência pronunciada em 27 de maio de I978, na Sorbonne perante a Société Française de Philosophie e publicada em seu Bulletin, intitulada Qu'est-ce que la critique?. ${ }^{23}$ Sem pretender uma descrição densa dessa conferência, convém tecer alguns breves comentários. Inicialmente, ele se refere à tradição ocidental, nos séculos XV e 
XVII, uma espécie de atitude crítica. Ela diz respeito à explosão, desde a Reforma, da arte de governar os homens, nos mais variados domínios: família, casa, exércitos, as crianças, os pobres, os mendigos, as cidades, os Estados e inclusive o próprio corpo. Tratou-se de uma invenção, a arte que é ao mesmo tempo pedagógica, mas também econômica e política. Simultaneamente, essa proliferação de artes de governança não pode ser desvinculada de uma atitude crítica, expressa na questão: “como não ser governado", que se poderia desdobrar em três proposições: primeira, uma atitude essencialmente espiritual que diz respeito a uma recusa à autoridade da Igreja e à busca de outros fundamentos de verdade nas Escrituras; em segundo lugar, uma atitude jurídica porque opõe a obrigação de obediência aos direitos naturais; e em terceiro lugar, não querer ser governado traduz a recusa em aceitar a autoridade como fonte de verdade. Foucault sustenta que

veremos que o núcleo da crítica é precisamente o feixe de relações que ata um a outro, ou um aos outros, o poder, a verdade e o sujeito. E, se a governamentalização é bem este movimento pelo qual se tratava na própria realidade de uma prática social de assujeitar os indivíduos pelos mecanismos de poder que invocam para si uma verdade, bem, eu diria que a crítica é o movimento pelo qual o sujeito se dá o direito de interrogar a verdade sobre seus efeitos de poder e o poder sobre seus efeitos de verdade; a crítica será a arte da não servidão voluntária, aquela da indocilidade refletida. A crítica teria essencialmente por função o desassujeitamento no jogo que se poderia nomear, numa palavra, de política da verdade (Foucault, 1990: 39).

Michel Senellart (I995) elaborou, de forma densa e detalhada, o estatuto da crítica enquanto crítica da razão governamental. Para tanto, ele se apoia, além do texto acima mencionado, no ensaio em que Foucault define a crítica a partir de uma leitura singular de parte da obra de Kant, remetida ao projeto de construir uma "ontologia do presente" (Foucault, I994, IV: 562-578), a par dos cursos. Foucault teria reconhecido, mesmo após suas críticas ao kantismo em As palauras e as coisas (I966), o propósito de Kant de fundamentar o estatuto da crítica, ainda que não tenha levado até as últimas consequências sua própria máxima crítica, qual seja "tenha a coragem de pensar por si mesmo". Ao ter deslocado a crítica para o plano exclusivo do saber, Kant teria neutralizado seus efeitos políticos. Daí porque, o problema da crítica, na esteira das tradições iluministas, teria se encerrado no domínio de uma ciência positivista do Estado. Foucault, em posição distinta e perfilando a tradição que vai da esquerda hegeliana aos teóricos da Escola de Frankfurt, se reconhece como partícipe daquelas tendências que manifestam "desconfiança crescente em relação à racionalização e a suas recaídas dominadoras” (Senellart, I995: 5). Daí porque se impõe repensar o iluminismo para "interrogar as racionalidades, tagarelas ou mudas, que nos conduzem. Consequentemente, ela implica que se inverta o procedimento kantiano, passando de uma crítica em termos transcendentais a uma crítica em termos de práticas imanentes" (6). É, portanto, sob este 
enfoque, que Senellart trabalhará a crítica como crítica da razão governamental, cuja tarefa é tripla: autocrítica (resistência ao poder), contracrítica (fabricação da liberdade) e radicalização crítica (superação dos limites ditados pela crítica à governabilidade).

É justamente aqui que reside o papel do intelectual. A experiência crítica é, por conseguinte, a da ultrapassagem, aquela que não se contenta em propor reformas, mas mudar maneiras de pensar que impossibilitam e travam transformações sociais. O intelectual universal, aquele que se apresentava como profeta e de certo modo a consciência avançada de seu tempo, cedeu lugar a um intelectual específico, nascido a partir da Segunda Grande Guerra e tendo por modelo o físico atômico, que desenvolveu uma relação específica e localizada entrecruzando sob novas bases as relações entre saber científico e instituição. A figura do intelectual universal, por excelência, era o grande escritor, o cantor da eternidade. Seu desaparecimento dá lugar a esse intelectual específico imerso em perigos de toda sorte e em lutas de diversa natureza (Foucault, I994, III: I40-I60). Ora, em que consiste o papel desse intelectual específico? "Existem momentos na vida onde a questão de saber se se pode pensar diferentemente do que se vê, é indispensável para continuar a olhar ou a refletir. [...] Mas, o que é filosofar hoje em dia - quero dizer, a atividade filosófica - senão o trabalho crítico do pensamento sobre o próprio pensamento? (Foucault, I 984: I3). Nisto consiste, ao final, a atitude crítica. Trata-se de uma recusa, de uma resistência, a de não se deixar ser governado pelos hábitos intelectuais, pelas verdades ditas. Para Foucault,

o trabalho de um intelectual não é modelar a vontade política dos outros; é, por meio das análises que ele faz nos domínios que são seus, reinterrogar as evidências e os postulados, sacudir os hábitos, as maneiras de fazer e de pensar, dissipar as familiaridades aceitas, retomar a medida das regras e das instituições a partir dessa reproblematização (em que ele desempenha o papel específico de intelectual) participar da formação de uma vontade política (em que ele tem seu papel de cidadão a desempenhar) (Foucault, I994, IV: 676).

Trata-se de um desconcerto, que requer uma espécie de fuga deliberada, de um escape das artimanhas proporcionadas pelas racionalidades dadas e reconhecidas como legítimas e imperativas. 
PERTURBAÇÕES: FOUCAULT E AS CIÊNCIAS SOCIAIS

Sérgio Adorno é doutor em sociologia pela USP, onde é professor titular de sociologia, e fez pós-doutorado no Centre de Recherches Sociologiques sur le Droit et les Institutions Pénales (Cesdip), na França. Foi diretor da FFLCH/USP (20I2-20I6); coordenador científico do Instituto Violência, Democracia e Segurança Cidadã (2009-20I5); coordenador da Cátedra Unesco de Educação para a Paz, Direitos Humanos, Democracia e Tolerância (2007-20I4); e é o atual coordenador científico do Núcleo de Estudos da Violência (NEV/USP) . 


\section{NOTAS}

* Agradeço especialmente ao pesquisador Herbert Rodrigues a criteriosa revisão dos originais.

I Uma das alunas desse curso, Maria Lúcia Montes, docente do Departamento de Antropologia da USP, tem anotações das aulas, que incluem uma reprodução pessoal de figura alusiva ao triedro dos saberes que compõe o capítulo final de Les mots et les choses.

2 Esse ciclo resultou na publicação de A verdade e as formas jurídicas, Cadernos PUC, Rio de Janeiro, n. I6, junho I974, durante muito tempo a única versão conhecida dessas originais conferências que antecipavam proposições posteriormente publicadas sob formulações mais precisas em Vigiar e punir (Foucault, I975) ao mesmo tempo em que outras proposições seriam deixadas de lado ou amenizadas em outras publicações e entrevistas. Em I990, apareceu uma edição em espanhol mais bem cuidada sob a responsabilidade de Enrique Lynch: La verdade y las formas jurídicas, México, Editorial Gedisa, curiosamente na colección Hombre y Sociedad. Durante muitos anos, essas conferências permaneceram desconhecidas do meio acadêmico francês, só sendo publicadas em I994, quando da primeira edição de Dits et écrits (Foucault, I994), II, I970I975, p. 538-646. Paris: Gallimard.

3 O Brasil estava sob vigência da ditadura militar. Na época, justamente no período em que as aulas estavam em curso, ocorreu a morte sob tortura do jornalista Vladimir Herzog, nas dependências do DOI-Codi, em São Paulo. O fato ensejou inúmeros protestos, entre os quais uma declaração pública de Foucault na qual manifestou sua decisão de suspender o curso e suas atividades acadêmicas, recusando-se a ensinar em um país que não respeitava as liberdades individuais e públicas, atitude que lhe granjeou profunda antipatia das autoridades políticas. Fui testemunha desses acontecimentos. Assisti às duas primeiras aulas e acompanhei seu desfecho. As informações sobre as visitas de Foucault ao Brasil foram extraídas de Eribon (I990).

4 Trata-se do artigo "Face aux gouvernements, les droits de l'homme", originalmente publicado em Libération, n. 967, 30-juin-I ${ }^{\text {er }}$ juillet, I984, p. 22. Ver Foucault (I994, II: 707-708). 
5 Tratei das influências do pensamento de Foucault na pesquisa brasileira (história, sociologia, antropologia, ciência política) cujos objetos empíricos se aproximavam daqueles do filósofo francês. Fiz um conciso balanço da apropriação de Foucault nos estudos sobre classe operária, cidades, instituições de controle social e educação publicados especialmente na década de I980. Ver Adorno (I99I), texto inicial do qual extraí partes na elaboração desta introdução. Não voltei mais a esse tipo de avaliação crítica. Outro pesquisador o fez de modo detido e metodologicamente bem conduzido, explorando as apropriações do pensamento de Foucault no domínio da educação; ver Aquino (2013).

6 Em várias de suas obras, há vezes em que o diálogo crítico é explícito, quando, por exemplo, se inclina a tecer agudas críticas às tradições marxistas e sua incorporação ao pensamento social moderno e contemporâneo. Outras vezes, esse diálogo não é explícito e requer do leitor certa familiaridade tanto com a obra de Foucault quanto com autores e obras subjacentes a esse exercício crítico. Essa dissimulação é particularmente presente em As palauras $e$ as coisas (1966), o que acaba por tornar sua leitura ainda mais árida e difícil. Não sem motivos, já ao final de sua trajetória intelectual, em uma de suas inúmeras entrevistas, disse que, fosse hoje, essa obra teria que ter sido escrita de modo completamente diferente do que o foi quando o debate intelectual estava muito polarizado em torno do estruturalismo e da hermenêutica.

7 Como sugerido, não abordarei neste artigo questões relacionadas à ética (hermenêutica), pois que se trata de um deslocamento no interior do problema da subjetividade que ensejaria reflexão mais longa do que pretendemos neste momento.

8 Menciono especialmente: Canguilhem (I994), Dreyfus \& Rabinow (I984), Gutting (I989), Habermas (I986), Owen (I994).

9 Os textos de Nietzsche que Foucault mobiliza para sustentar seus argumentos encontram-se referenciados no corpo dos textos que compõem Dits et écrits (1994). Na expectativa de que suas leituras singulares das obras de Nietzsche seriam inevitavelmente censuradas, Foucault 
se antecipou às críticas justificando-as como um ato de liberdade em face de seus interesses de investigação histórica. Ver Foucault (1994, II: 740-753).

Io Em um texto anterior, "Nietzsche, la généalogie, l'histoire. Hommage à Jean Hyppolite", de I97I, em que apresenta os fundamentos da genealogia, Foucault (I994, II: I36-I56) precisa melhor o significado da palavra invenção, na esteira do emprego da palavra alemã por Nietzsche. Invenção é utilizada por oposição à origem. Nesse sentido, a genealogia se opõe à pesquisa da origem.

I I Por certo, esse trabalho de desconstrução do sujeito transcendental do conhecimento foi realizado com minúcias em As palauras e as coisas (I966), contudo sob a perspectiva da crítica arqueológica dos discursos. Como se sabe, o objeto dessa obra é o aparecimento do homem como acontecimento discursivo moderno. A arqueologia é, nesse universo, uma atitude crítica capaz justamente de introduzir uma fissura na finitude do homem como sujeito e ao mesmo tempo objeto do conhecimento, como aquele sobre o qual o conhecimento se debruça e ao mesmo tempo determina as condições e possibilidades do próprio conhecimento do homem. Levada às últimas consequências, a crítica arqueológica dessa espécie de epistemologia moderna só poderia conduzir à decretação da morte do homem, esse sujeito transcendental herdeiro da tradição kantiana.

I 2 Entrevista a Madeleine Chaptal, originalmente publicada em La Quinzaine Littéraire, n. 5, I6 mai 1966: I4-I5. Pessoalmente, compreendi melhor o alcance dessa proposição lendo Guimarães Rosa que, em obra literária, afirmou algo do gênero: "o que existe é homem humano". Pois, Foucault se propôs com a crítica arqueológica justamente eliminar o adjetivo humano do homem. Tratá-lo como tal, como aquele que trabalha, vive e fala.

I3 A noção de "a priori histórico" está definida no capítulo introdutório de As palauras e as coisas (I966). Os códigos fundamentais de uma cultura fixam para cada homem as ordens empíricas com que terá que lidar. Na outra extremidade do pensamento encontram-se as teorias científicas ou as interpretações filosóficas que buscam explicar por que uma ordem existe e é preferível em relação a outras possíveis. 
Entre esses dois extremos, há uma zona confusa, obscura que cabe à análise arqueológica conhecer. Entre o olhar codificado e o conhecimento reflexivo, há uma região mediana que liberta a ordem em seu ser mesmo (Foucault, I966: I2-I3). O "a priori histórico" moderno é justamente a emergência do homem no interior dos saberes. É nesse sentido que a arqueologia das ciências humanas atravessa três grandes ordens de saber: o conhecimento a partir das similitudes, o nascimento das ciências empíricas e o surgimento dos saberes do homem como representação. Ver também Arqueologia do saber (I972), especialmente item V do capítulo III, O enunciado do arquivo.

I4 São os seguintes os cursos: Lessons sur la volonté de savoir (I970-I975); Théories et institutions pénales (I97I-I972); La société punitive (I972-I973); Le pouvoir psychiatrique (I973-1974); Les anormaux (I974-I975); Il faut défendre la société (I975-1976); Sécurité, territoire, population (I977I978); Naissance de la biopolitique (I978-I979); e Du gouvernement des vivants (I979-I980).

I5 Tratei deste procedimento, o que é um autor, no artigo "O autor nos escritos de Foucault: entre o discurso e a morte" (Adorno, 20I2).

I6 Acontecimento é um conceito-chave no pensamento de Michel Foucault. Na arqueologia, ele se refere com frequência aos acontecimentos discursivos. Afirma que a arqueologia não se interessa pelo encadeamento dos acontecimentos empíricos; todavia, se interessa pelo modo como uma formação discursiva vem substituir outra a partir de uma ruptura, por exemplo, na ordem dos saberes: o surgimento das ciências empíricas e as mudanças na representação da era clássica ou a abertura dos cadáveres e o nascimento da clínica alterando os saberes médicos. Posteriormente, o conceito passa a ser empregado com mais frequência nas análises genealógicas, como uma irrupção de singularidades históricas que demarcam mudanças nas formas de assujeitamento. Enquanto tal, a noção de acontecimento vem associada à de atualidade, à de história do presente (ver Ewald, I997: 203-2 I2). Sob essa perspectiva, analisando a revolução como um acontecimento, Foucault (2008: 3-24) diz que o acontecimento não é propriamente os seus efeitos revolucionários ou a reviravolta que institui o progresso moderno; 
o acontecimento diz respeito ao modo como a revolução se torna um espetáculo, isto é, a forma como é acolhida pelos seus contemporâneos que não participam diretamente, mas a acompanham em seus gestos e sinais.

I7 A tradução brasileira desse ensaio encontra-se em Foucault (I979: 15-37).

I8 Veja-se, a respeito, o debate entre Foucault e os historiadores em L'impossible prison, organizado por Michele Perrot (I980). Vários historiadores advertem Foucault de erros no tratamento de fontes históricas bem como de haver generalizado o modelo francês de prisão para o conjunto de outras instituições existentes em outras sociedades na mesma época, em particular aquelas da Grã-Bretanha, dos Estados Unidos e da Austrália. Foucault (I984: I3) responde que seu objeto não era a prisão e que ele não se reconhecia como historiador. A propósito, referindo-se ao deslocamento teórico de uma história da sexualidade para uma história do sexo, afirmou: "os estudos que se seguem, assim como outros que anteriormente empreendi, são estudos de 'história' pelos campos que tratam e pelas referências que assumem; mas não são trabalhos de "historiador'”.

I9 O projeto trataria das relações entre a carne e o corpo (vol. II), a cruzada infantil contra a masturbação (vol. III), a mulher, a mãe e a histérica (vol. IV), os perversos (vol. V) e população e raças (vol. VI). Como projetado, nunca chegou a ser executado, não obstante Foucault tenha dado entrevistas, compiladas em Dits et écrits (I994, v. III). Ele procurou justificar o abandono do projeto na introdução do volume 2 de A história da sexualidade - o uso dos prazeres (I984). Suspeita-se que o projeto original o levaria a ter de confrontar-se com Freud e a psicanálise. Certamente, depois do confronto com Kant, Hegel e Marx, esse propósito exigiria um outro investimento de investigação. De todo modo, alguns dos temas foram tratados nos cursos. Por exemplo, no curso de I975-1976, publicado em Em defesa da sociedade (Foucault, I999), ele abordou a questão do racismo.

20 Esse tema é particularmente trabalhado nas aulas de 25 de janeiro e de Io de fevereiro de I978. Na sequência, Foucault abordará as conexões entre as teorias contratualistas e as tecnologias de biopolítica, aprofundará a discussão sobre o problema do governo nos séculos XVII e XVIII, e desen- 
volverá uma longa discussão sobre a questão da governabilidade, centrada em torno do poder pastoral e das práticas de condução da conduta.

2I No texto de Ewald, essa análise das relações poder/produção, sob a perspectiva de uma anatomia política da economia política é bem mais detalhada do que está anunciada neste texto. Ver especialmente as páginas I240 a I246, nas quais há uma interessante análise da funcionalidade política do trabalho penal, o trabalho realizado pelos presos. Foucault teria mostrado que, num primeiro momento, prevaleciam fundamentos morais e moralizante a respeito das virtudes do aprendizado do trabalho disciplinado e rotineiro pelos presos, pois se julgava que uma das explicações para o crime e a delinquência tinha a ver com a vagabundagem e a recusa ao trabalho fabril. Em um segundo momento, já no século XIX, as modalidades e técnicas de trabalho empregadas nas prisões tem por efeito consolidar a sua inutilidade e firmar o entendimento segundo a qual a recuperação e reforma dos presos eram fins mentirosos.

22 Ver "La société disciplinaire en crise". Conférence à l’Institut franco-japonais de Kansai, à Kyoto, le I8 avril I978, publicada em Foucault (I994, III: 532-534).

23 Sabe-se que essa sociedade manifestava certo desconforto de reconhecer Foucault como filósofo. Apenas em duas oportunidades ele foi convidado para apresentar conferência. A primeira, em 22 de fevereiro de 1969, em que apresentou o tema "Qu'est-ce qu'un auteur?", publicado no Bulletin de la Société Française de Philosophie, 63e année, n. 3, juillet-septembre, I969, p. 73-I04 (ver Foucault, I994, I: 78982I). A segunda vez justamente para apresentação da conferência sobre o que é a crítica: "Qu' est-ce que la critique?", publicada no Bulletin de la Société Française de Philosophie, 84e année, n. 2, avril-juin, I990, p. 35-63 (não publicada nessa edição de Dits et écrits).

\section{REFERÊNCIAS BIBLIOGRÁFICAS}

Adorno, Sérgio. (20I2). O autor nos escritos de Foucault: entre o discurso e a morte. Jornal de Psicanálise, 45/82, p. II3I 28. 
Adorno, Sérgio. (I99I). Sujeito, história e poder. Estudos de Sociologia. Série Textos. São Paulo: Departamento de Sociologia, Faculdade de Filosofia, Letras e Ciências Humanas, Universidade de São Paulo.

Aquino, Júlio Groppa. (2013). A difusão do pensamento de Michel Foucault na educação brasileira: um itinerário bibliográfico. Revista Brasileira de Educação, I8/53, p. 30I-324.

Canguilhem, Georges. (1994). The Death of Man, or Exhaustion of the Cogito? In: Gutting, Gary (ed.). The Cambridge Companion to Foucault. New York: Cambridge University Press, p. 7I-9I.

Davidson, Arnold I. \& Gros, Frédéric. (2004). Michel Foucault. Philosophie. Anthologie. Paris: Gallimard.

Dreyfus, Hubert \& Rabinow, Paul. (1984). Michel Foucault: un parcours philosophique. Paris: Gallimard.

Eribon, Didier. (I990). Michel Foucault: uma biografia. São Paulo: Companhia das Letras.

Ewald, François. (I997). Foucault et l'actualité. In: Franche, Dominique et al. Au risque de Foucault. Paris: Centre Georges Pompidou/Centre Michel Foucault, p. 203-2I2.

Ewald, François. (1975). Anatomie et corps politiques. Critique, 343, p. I228-1265.

Foucault, Michel. [196I] (20I0). História da loucura. São Paulo: Perspectiva.

Foucault, Michel. (2008). Le gouvernement de soi et des autres. Cours au Collège de France (I982-I983). Paris: EHESS/Gallimard/Seuil.

Foucault, Michel. (2004). Sécurité, territoire, population. Cours au Collège de France (I977-I978). Paris: Gallimard/Seuil.

Foucault, Michel. (2002). A verdade e as formas jurídicas. 3.ed. Tradução de Roberto Machado e Eduardo Jardim Moraes. Rio de Janeiro: Nau Editora.

Foucault, Michel. (1999). Il faut défendre la société. Cours au Collège de France (I975-I976). Paris: Gallimard/Seuil.

Foucault, Michel. [1963] (1997). Naissance de la clinique. Paris: Quadrige/Presses Universitaires de France.

Foucault, Michel. (1994). Dits et écrits, I954-I988. Paris: Gallimard (4 volumes). 
Foucault, Michel. (I990). Qu'est-ce que la critique? Critique et Aufklärung. Bulletin de la Société Française de Philosophie, $82 / 2$, p. $35-63$.

Foucault, Michel. (1984). História da sexualidade II: o uso dos prazeres. Rio de Janeiro: Graal.

Foucault, Michel. (I979). Microfísica do poder. Org. Roberto Machado. Rio de Janeiro: Graal.

Foucault, Michel. (1977). História da sexualidade I: a vontade de saber. Rio de Janeiro: Graal.

Foucault, Michel. (1975). Surveiller et punir. Naissance de la prison. Paris: Gallimard.

Foucault, Michel. [1969] (I972). The archaelogy of knowledge. London: Tavistock Publications.

Foucault, Michel. (I97I). L'ordre du discours. Leçon inaugurale au Collège de France prononcée le 2 décembre I970. Paris: Gallimard.

Foucault, Michel. (1966). Les mots et les choses. Une archéologie des sciences humaines. Paris: Gallimard.

Goffman, Erving. (I96I). Asylums: essays on the social situation of mental patients and other inmates. Garden City: Anchor Books.

Gutting, Gary. (1989). Michel Foucault's archaeology of scientific reason. New York: Cambridge University Press.

Habermas, Jürgen. (I986). Une flèche dans le coeur du temps présent. Critique, 47I-472, p. 794-799.

Owen, David. (1994). Maturity and modernity. Nietzsche, Weber, Foucault and the ambivalence of reason. London/New York: Routledge.

Perrot, Michelle (org.). (1980). L’impossible prison: recherches sur le système pénitentiaire au XIX ${ }^{\text {ème }}$ siècle. Paris: Seuil.

Senellart, Michel. (I995). A crítica da razão governamental em Michel Foucault. Tempo Social: Revista de Sociologia da USP, 7/I-2, P. I-I4.

Veyne, Paul. (1984). Como se escribe la história: Foucault revoluciona la historia. Madrid: Alianza Editorial.

Thompson, E. P. (1963). The making of the English working class. New York: Vintage Books. 


\section{Palavras-chave \\ Foucault; \\ sujeito; \\ história; \\ poder;}

verdade e crítica.

\section{PERTURBAÇÕES:}

\section{FOUCAULT E AS CIÊNCIAS SOCIAIS}

Resumo

O artigo discute o diálogo, por vezes ácido, por vezes irônico, entre o pensamento de Michel Foucault e as tradições das ciências sociais e das humanidades. Como Foucault afirmou, o pensamento é feito para cortar. Por seu itinerário de investigação histórica, essa exigência introduziu perturbações em nossas convenções intelectuais, em nossos hábitos de pesquisa, em nosso arsenal metodológico posto à disposição para explicar realidades sociais. Trata-se, portanto, de um pensamento provocativo. Com esse fim, busca-se apresentar um pequeno inventário dessas perturbações, em torno de alguns eixos e hipóteses que permitam, ao final, uma reflexão sobre o estatuto da crítica no interior do pensamento do filósofo francês.

\section{DISRUPTIONS:}

\section{FOUCAULT AND THE SOCIAL SCIENCES}

Keywords Abstract

Foucault; The article discusses the sometimes acerbic, sometimes subject; history; ironic, dialogue between the thought of Michel Foucault and the traditions of the social sciences and the humanipower; ties. As Foucault affirmed, thought is made to be cutting. truth and critique. Pursuing his itinerary of historical investigation, this requirement ended up disrupting our intellectual conventions, our research habits and our methodological toolbox filled with ready-made explanations of social realities. Hence his thought is provocative in kind. The aim here is to present a small inventory of these disruptions, pursuing various lines of inquiry and hypotheses that allow us to conclude with a reflection on the status of critique in the French philosopher's thought. 